\title{
Performance Evaluation of Jatropha Seed Oil and Mineral Oil-Based Cutting Fluids in Turning AISI 304 Alloy Steel
}

\author{
Awode Emmanuel Imhanote, Abolarin Matthew Sunday, Lawal Sunday Albert, Adedipe \\ Oyewole
}

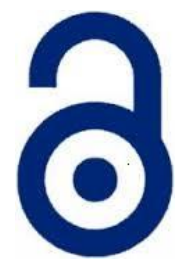

Received: 22 April 2020

Accepted: 01 July 2020

Published: 30 July 2020

Publisher: Deer Hill Publications

(c) 2020 The Author(s)

Creative Commons: CC BY 4.0

\begin{abstract}
Cutting fluids play a major role in machine operations, life of tools, workpiece quality and overall high productivity which are considered as potential input for minimal tool wear, minimal surface roughness and better machining finished product owing to the ability to prevent overheating of the workpiece and cutting tool. In this paper, the challenge of environmental biodegradability, tool wear and workpiece surface roughness prompt the need to evaluate and compare the performance of Jatropha oil based cutting fluid (JBCF) with mineral oil based cutting fluid (MBCF) during turning with AISI 304 Alloy steel which are presented. Test were conducted on the Physiochemical property, fatty acid composition (FAC), cutting fluids formulation of oil ratio to water ratio in proportion of 1:9, turning operation and response surface methodology (RSM) design of experiment were carried out and used respectively. Results from FAC indicated that jatropha seed oil (JSO) has an approximately $21.6 \%$ saturated fat with the main contributors being $14.2 \%$ palmitic acid. The physiochemical property results show $\mathrm{pH}$ value 8.36 , Viscosity $0.52 \mathrm{~mm}^{2} / \mathrm{s}$, resistant to corrosion, good stability and a milky colouration. The $\mathrm{S} / \mathrm{N}$ ratio for main effect plot for JBCF and MBCF stand at 1250 CS, $1.15 \mathrm{FR}$ and $0.65 \mathrm{DOC}$; and $500 \mathrm{CS}, 1.15 \mathrm{FR}$ and 0.65 respectively with R-sq $=85.14 \%$ and $\mathrm{R}$-sq(adj) $=71.76 \%$ for JBCF Ra and R-sq $=71.24 \%$ and $\mathrm{R}$-sq(adj) $=56.35 \%$ for JBCF Tw, compared to R-sq $=84.44 \%$ R-sq(adj) $=70.43 \%$ is for MBCF Ra, and R-sq $=70.48 \%$ and R-sq(adj) $=55.92 \%$ for MBCF Tw. Conclusively, JBCF exhibit minimal surface roughness, minimal tool wear, minimal environmental biodegradability and overall better performance compare to MBCF which makes it more suitable for turning of AISI 304 Alloy steel and is in good agreement with previous work.
\end{abstract}

Keywords: Evaluation, Performance, Cutting fluid, Turning, Jatropha oil, Mineral oil.

\section{INTRODUCTION}

The understanding of cutting fluids performance in turning process is very important in order to improve the efficiency of the process [1]. Cutting fluids have been widely employed and have often been viewed as required addition to high quality machining and high productivity. Cutting fluid affect the productivity of machining operations, tool life, quality of workpiece as well as prevent the overheating of the workpiece and cutting tool [2]. The three basic ways to which cutting fluids contribute to machining process were investigated [3]. First, it acts as lubricant by reducing friction, it reduces the heat generated. Secondly the cutting fluid must also act as an effective coolant, because frictional heating cannot be completely eliminated and often, not even substantially reduced. Finally, it should act as an anti-weld agent by washing away the chips to counteract the tendency of the work material to weld the tool under heat and pressure. Although, cutting fluids have greatly improved machining performance, conventional metal cutting fluids have more recently become a source of non-value added cost to businesses in machining industry. As environmental and regulatory burdens become onerous, profit margins for these enterprises decrease. With the introduction of ISO14000 environmental series legislation, industry users of lubricants are encouraged to reduce or eliminate or change metal cutting fluids from their processes to more environmentally friendly substances [4] and [5]. The $\mathrm{pH}$ value is a measure of a fluid acidity or alkalinity. Alkalinity range is very important when it comes to cutting fluid [6]. The process of efficiently cutting away materials in the form of chips

E.I. Awode $₫$, M.S. Abolarin², S.A. Lawal'2, O. Adedipe ${ }^{2}$

Department of Mechanical Engineering

'Air Force Institute of Technology, Kaduna, Nigeria

2Federal University of Technology, Minna- Nigeria

E-mail: e.awode@afit.edu.ng; greatawode@gmail.com

Reference: Awode, E. I. Lawal, S. A., Abolarin, M. S., and Adedipe, O. (2020). Performance Evaluation of Jatropha Seed Oil and Mineral Oil-Based Cutting Fluids in Turning AISI 304 Alloy Steel. International Journal of Engineering Materials and Manufacture, 5(3), 85-97. 
which involve the exertion of high force on the workpiece by the cutting tool is known as machining operations [7]. A considerable amount of heat is generated near the cutting edge of the cutting tool by the high forces as a result of friction between the tool and the workpiece, and partly by the action of the material shearing process. [8], conducted a comprehensive review on the application of vegetable oil-based metalworking fluids (MWFs) in machining ferrous metals. The cause of heat and friction were removed when vegetable oil-based MWFs were employed, which made provision for lubrication between chips of both interfaces. Accelerated tool wear, shortened tool life and in most cases, created poor surface quality as a result of tool temperature and the increased friction normally experienced during machining. Cutting fluids therefore, play the role of reducing heat, tool-chip-workpiece interface lubrication for lower friction and removal of chips from the cutting zone. The formulation of cutting fluids for machining operations have been made possible by the use of plant seed oils of different kinds. These seed oil cutting fluids have demonstrated potential as futuristic cutting fluids. Their performance is as good as or even better than similar mineral oil based cutting fluids. These plant seed oil based cutting fluid have noticeably stood out due to their biodegradability and non-toxic properties. Jatropha curcas oil in recent time, is beginning to be a house hold name in Nigeria, owing to the abundance of rich content it possesses.

This work employed Response surface methodology (RSM) experimental design. RSM is a statistical software model for measuring and exploring the relationship between several explanatory variables and one or more response variables. The chosen design of experiment (DOE) method is the response surface methodology (RSM) for the following reasons: The RSM is the most user friendly and effective which leads to more accurate and powerful test by reducing error variance; It provides better precision which can be obtained in estimating the overall main factor effects; and Interaction between different responses can be properly identified and explored without confounding the effects.

\subsection{MATERIALS AND METHOD \\ 2.1 Materials}

\subsubsection{Vegetable oils}

Jatropha Curcas oil (JCO) (extracted from Jatropha curcas seeds) used, was obtained from AgriEnergy Nigeria, sourced from Technology Incubation Centre (TIC) complex farm centre, Kano state and Mineral soluble oil (MSO) was sourced from Agarawu market in Lagos highland, Lagos state.

\subsubsection{Turning Operation Component Materials}

The workpiece material for this study is an austenitic chromium-nickel stainless steel categorised as AISI 304 also referred to by its old name 18/8, being $18 \%$ chromium and $8 \%$ nickel. The cutting tool and tool holder used for this work is RP8025 CNMG120404-PM 3688-288L 10PCS tungsten carbide insert per pack and MTJNR 2020 K16 Cutting tool insert holder respectively, on a model MOOL Lathe 37475.

\subsection{Methodology}

\subsubsection{Determination of Physicochemical Properties}

The physicochemical properties of the Jatropha curcas seed oil as shown in Table 1 was determined at the Department of Water Resources, Aquaculture and Fisheries Technology (WAFT) Laboratory, School of Agriculture and Agricultural Technology (SAAT), Federal University of Technology, Minna, Niger State, while the determination of fatty acid composition was conducted at the American University of Nigeria, Yola. The following parameters were determined: (i) $\mathrm{pH}$ value (ii) Acid V mgKOH/g (iii) Specific Gravity (iv) Viscosity @40ㄷ, (v) Flash point, (vi) Saponification (vii) Pour Point (viii) Peroxity (ix) Fatty acid composition (FAC). The standard method used in determining the physicochemical properties of the vegetable oils is presented in Table 1.

\subsubsection{Formulation of the cutting fluids}

\subsubsection{Additives}

One of the very important constituents in the formulation of cutting fluids is additives. The additives used are: (i). Anti-corrosion agent (ii). Anti-oxidant agent (iii). Biocide and (iv). Emulsifier. These additives, aside anti-corrosion agent, were prepared in the Chemical Engineering laboratory of Federal University of Technology, Minna- Nigeria. Banana plant juice sourced locally from Minna, Niger State- Nigeria was used as anti-corrosion. Cutting fluid preparation was based on percentage ratio of oil to water and other additives as 1: 9 . The preparation approach was primarily on the method adopted by [8], [9], and [10]. A controlled condition for addition of the additives to the oil was done in the procedure to the formulation of the vegetable oil. For each mixture, a time of 12 min was observed at ambient temperature using a local made mechanical stirrer as shown in Figure 1. Different additives were added to the jatropha seed oil, including emulsifier, antioxidant, anti-corrosive and biocide in different percentages, and mixed thoroughly with a mechanical stirrer. Water was added to a percentage volume of 90 , thus making the emulsion ratios of 1:9 of base oil (Jatropha seed oil) and water. Three readings of viscosity and $\mathrm{pH}$ value were measured. The percentage ratio of additives used by [9], was adopted for the formulation, which are as follows: 9.35\% emulsifier, $0.97 \%$ biocide, $10.61 \%$ anticorrosive agent, $0.64 \%$ antioxidant as shown in Table 2 .

The purpose for adopting the percentage ratio used by [9], was based on the suitable output obtain in terms of stability, $\mathrm{pH}$, corrosion level and viscosity during the formulation. The formulation involved the mixture of oil and 
additives and stirrer before the balance for the required volume was made from water. The following calculation was used to obtain the appropriate volume of each component in preparation of one litre (1000ml) of cutting fluid. Mixing the soluble oil (concentrate) with water at the ratio of 1: 9: was applied in the formulation of mineral based cutting fluid. The materials for the formulations were: i. Additives (emulsifier, antioxidant, anti-corrosion and biocide) and ii. Jatropha seed oil while, the following equipment were also used: i) beaker- mini and medium test tubes, ii) distilled water filter paper, iii) bowls and dishes, iv) improvised mechanical stirrer, $v$ ) drilling machine, vi) electronic scale as shown in Figure 2, and vii) stop watch.

\subsubsection{Gas Chromatography and Mass Spectrometer}

A mass spectrometer (GC-MS) instrument GC-MS-QP2010 Shimadzu system, from Japan was used to analyse the Fatty Acid Composition (FAC), which was conducted using a gas chromatograph interface. The following machine conditions were used: Column over temperature of $70.0^{\circ} \mathrm{C}$; injection temperature of $250.0^{\circ} \mathrm{C}$; Column flow was $1.80 \mathrm{~mL} / \mathrm{min}$ with total flow of $40.8 \mathrm{~mL} / \mathrm{min}$ at linear velocity of $49.2 \mathrm{~cm} / \mathrm{sec}$ and pressure of $116.9 \mathrm{kpa}$. The FAC analysis results for the vegetable oil (Jatropha seed oil) is presented in Figure 3. The formulation processes of cutting fluid is as follows: i. additives selection ii. Mixing iii. Cutting emulsion verification. This process was adopted from [11].

\subsubsection{Characterisation of Formulated Cutting Fluids}

\section{(a) $\mathrm{pH}$ Value}

The $\mathrm{pH}$ values of the cutting fluid were measured using $\mathrm{pH}$ meter in the Chemical Laboratory of Federal University of Technology, Minna, Niger State of Nigeria. A standard solution was employed in calibration of the $\mathrm{pH}$ meter. Distilled water was used to clean the electrode of the $\mathrm{pH}$ meter before taking each reading. The $\mathrm{pH}$ value for the individual three samples for the JBCF (JA, JB and JC) are presented in Table 5.

Table 1: Jatropha oil Physiochemical Properties

\begin{tabular}{|c|c|c|}
\hline \multirow{2}{*}{$\begin{array}{c}\text { Property } \\
\text { Snecific oravity }\end{array}$} & Method & Description \\
\hline & weight of oil & The weight of oil was compared to the weight of an equal \\
\hline & $\begin{array}{c}\text { weight of equal vol } \\
\text { of water }\end{array}$ & $\begin{array}{l}\text { volume of distilled water to determine the specific gravity } \\
\text { of the extracted oil by using a specific gravity bottle. }\end{array}$ \\
\hline \multirow[t]{2}{*}{ Viscocity@40C } & ASTM D445 and ISO 3104 & Equation used was: \\
\hline & & $\frac{\eta}{d t}=A-B t^{2}$ \\
\hline Acid value & Acid value $\mathrm{mg} / \mathrm{KOH} / \mathrm{g}$ & $=\underline{\text { Titre value } x 0.1 \mathrm{M} \mathrm{KOH} x 56.10}$ \\
\hline Peroxity & ASTM DD5348 & $\begin{array}{l}\text { weight of sample }(g) \\
\text { The muffle furnace was used to heat the oil } \\
\text { Till weight remain constant }\end{array}$ \\
\hline Flash Point & ASTM D93 & $\begin{array}{l}\text { The flash point tester was used to determine the flash point } \\
\text { of the various sample }\end{array}$ \\
\hline $\begin{array}{l}\text { Saponification } \\
\text { value }\end{array}$ & ASTM D558 & $\begin{array}{l}\text { The conversion of fat, oil or lipid formed into alcohol and } \\
\text { soap by the action of heat with } \mathrm{NaOH} \text {. }\end{array}$ \\
\hline $\mathrm{pH}$ value & & $\begin{array}{l}\text { The } \mathrm{pH} \text { values of the vegetable oils were determined using } \\
\text { the } \mathrm{pH} \text { meter. }\end{array}$ \\
\hline Density @ 15 C & ASTM D4052 & Specific Gravity (SG) $=\frac{\text { Weight of Xml of oil } \times 0.1 \times 12.69}{\text { Weight of Xml of Water }}=\frac{B-A}{C-A}$ \\
\hline
\end{tabular}

Table 2: Cutting fluid formulation formula samples

\begin{tabular}{|l|l|l|l|l|}
\hline Sample & Emulsifier & Biocide & Anti-Corrosion & Anti-oxidant \\
\hline C & $9.35 \%$ & $0.97 \%$ & $10.61 \%$ & $0.64 \%$ \\
\hline
\end{tabular}

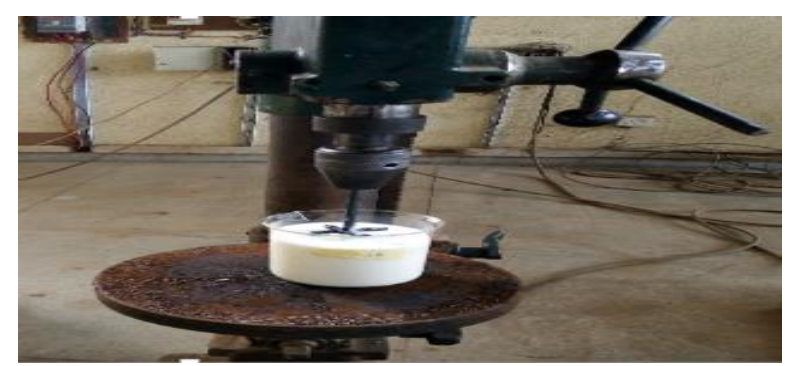

Figure 1: Stirring oil-in-water mixture

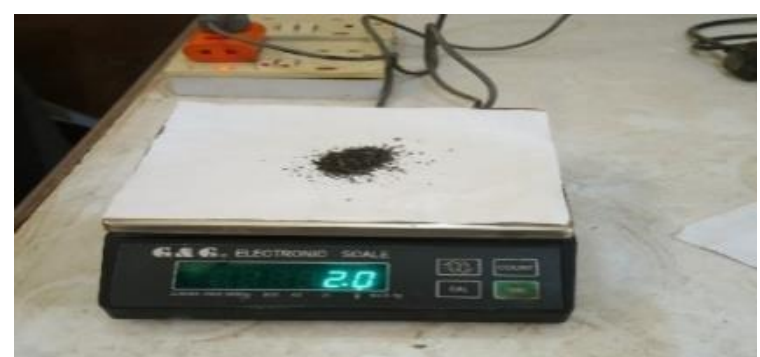

Figure 2: Electronic scale used for measuring cast iron chips for corrosion test. 
(b) Viscosity

The Chemical Engineering Laboratory of the School of Infrastructure, Process Engineering and Technology, Federal University of Technology, Minna in Niger State, Nigeria was where the formulated cutting fluid viscosity was determined using ASTM D445 standard.

\section{(c) Corrosion Level Test}

The formulated cutting fluid corrosion level was determined using the ASTM D4627 cast iron chips on filter paper, and the method adopted by [12]. However, this test was carried out to evaluate the number of corrosion spots on a test filter paper, from the formulated vegetable cutting fluids corrosive action(s). The experiment was carried out by measuring $2 \mathrm{~g}$ of cast iron chips on a filter paper and placed on the G\&G electronic scale as shown in Figure 2. The particular $2 \mathrm{ml}$ vegetable oil cutting fluid collected was stirred and gradually poured on the iron chips in a baker, and then shaken for 2 minutes to mix the chips and fluid. The fluid was decanted and chips placed on a filter paper for 2 hours. Thereafter, the iron chips were removed and the filter paper carefully rinsed out with tap water.

\section{(d) Stability}

For purpose of stability the formulated cutting fluids were evaluated using a visual transparency within a period of 72 hours at room temperature $\left(25^{\circ} \mathrm{C}\right)$ as to separation of water and oil in a graduated $1000 \mathrm{ml}$ test tubes.

\subsubsection{Machining Operation Methodology}

In this experimental study design, turning operation was employed and the machining parameters such as cutting speed, feed rate and depth of cut (DOC) are of key importance as input factors. Also, the two cutting fluids being investigated and evaluated had effect on the tool wear and surface roughness of the workpiece and therefore are also input factors considered. Hence, the experiments design factors are i) cutting speed (A), ii) feed rate (B), iii) depth of cut (C) and iv) types of cutting fluids (D), in this study are JBCF and MBCF; and commercially available mineral oil based cutting fluids. Two experimentation levels are chosen as low $(-1)$ and high $(+1)$ with the two different oil based cutting fluids of 20 runs each and a total 40 runs. Tables 3 showed some DOE methods with the criteria for selection. There are three (3) factors in the present study which was tested at two (2) levels; therefore, leading to a $2^{3}$ factorial design. A total of 20 runs each $\left(2^{3}\right)$ of experiments was performed for the two different oil based cutting fluids as shown in Table 3.

\subsection{RESULTS AND DISCUSSION}

\subsection{Physiochemical Properties of Jatropha Seed Oil}

The physiochemical properties of the jatropha were tested in the Department of Water Resources and Fisheries Technology of the Federal University of Technology, Minna. The test analysis carried out highlighted the physical and chemical characteristics of this oil. Table 4 shows the physiochemical properties of the oil. The weight of oil was compared to the weight of an equal volume of distilled water to determine the specific gravity of the extracted oil by using a specific gravity bottle to determine the specific gravity. The flash point tester was used to determine the flash point of the various sample. The $\mathrm{pH}$ values of the vegetable oil were determined using the $\mathrm{pH}$ meter, while other parameters were determine using existing formulae. A standard solution was employed in calibration of the $\mathrm{pH}$ meter. Distilled water was used to clean the electrode of the $\mathrm{pH}$ meter before taking each reading.

\subsubsection{Gas Chromatography Mass Spectrometer (GC-MS) Analysis}

The fatty acid composition or profile for the Oil sample is shown in Figure 4 showing the mass spectrum for JSO analysis. The fatty acid composition results for the two oils samples indicated that jatropha seed oil (JSO) has an approximately $21.6 \%$ saturated fat with the main contributors being $14.2 \%$ palmitic acid, $7 \%$ stearic acid and $0.4 \%$ Other acids. On the other hand, $78.4 \%$ of jatropha seed oil is unsaturated fat with $44.7 \%$ oleic acid (monounsaturated) and $32.8 \%$ linoleic acid (polyunsaturated).

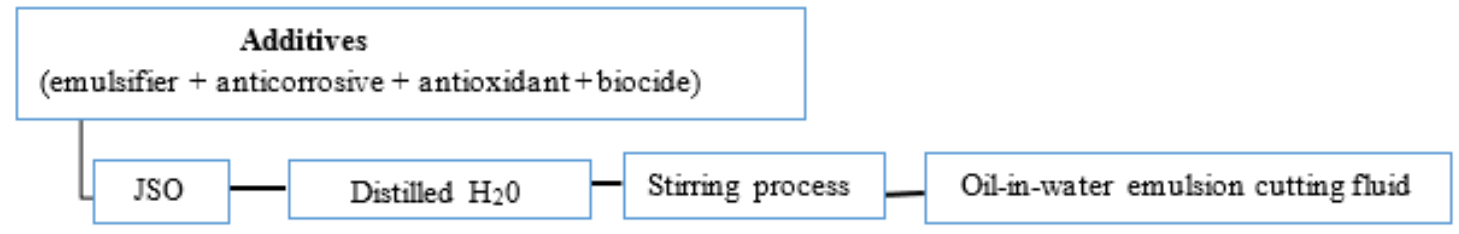

Figure 3: Schematic diagram of the oil in water mixture

Table 3: Cutting parameters and levels

\begin{tabular}{ccccc}
\hline Factor & Unit & $\begin{array}{c}\text { Level 1 } \\
\text { Low }(-1)\end{array}$ & $\begin{array}{c}\text { Level 2 } \\
\text { High }(+1)\end{array}$ & Types of cutting fluid \\
\hline Cutting speed (A) & $\mathrm{m} / \mathrm{min}$ & -1 & +1 & JSO \\
Feed rate $(\mathrm{B})$ & $\mathrm{mm} / \mathrm{rev}$ & -1 & +1 & $\mathrm{MBO}$ \\
\hline
\end{tabular}


The $\mathrm{pH}$ value is a measure of a fluid acidity or alkalinity of the three samples of jatropha [Jatropha sample A (JA), Jatropha sample $B(J B)$ and Jatropha sample $C(J C)$ ]. The value of JC (8.70) is higher and was adopted in this study. The ability of a fluid to resist flow is known as viscosity. An acceptable cutting fluid should have moderate viscosity which enable pumping from the sump through hoses and pipes into the cutting zone to permeate the tool-chip interface for cooling to remove the heat generated and for lubrication to reduce friction and heat. JB and JC value in Table 6 gave an appreciable value which consistent with the work of [12]. The three different formulated samples of $\mathrm{pH}$ and viscosity for JSO with JC been the most suitable formulation [11] and was adopted as shown in Table 7.

The varying samples of the different formulae used in the three experiments carried out shows that sample JC whose values for $\mathrm{pH}$, stability, viscosity and stability were consistent with existing aforementioned literatures and thus adopted in the preparation of the vegetable oil cutting fluids. The mixture stirring time was $12 \mathrm{~min} / \mathrm{sample}$. The measuring tube maximum level was $100 \mathrm{ml}$. the angle speed from the stirrer is $1400 \mathrm{rev} / \mathrm{min}$. the starting day/time was 1/ 2:30pm. These procedures was used for the stabilities of the three jatropha oil based cutting fluid sampled. All the samples passed stability test. However, JA (Jatropha seed oil based cutting fluid sample A) presented higher stability test conditions with stability value in Table 8 been higher than samples B and $C$.

Table 4: Physiochemical properties of Jatropha Seed Oil (JSO)

\begin{tabular}{lc}
\hline Physiochemical Properties & JSO Sample \\
$\mathrm{pH}$ value & 6.35 \\
Acid Value mgKOH/g & 4.86 \\
Specific Gravity & 0.907 \\
Viscosity @40 C & 21.30 \\
Flash Point & 260 \\
Saponification & 194 \\
Pour Point & -1 \\
Peroxity Value & 6.20 \\
\hline
\end{tabular}

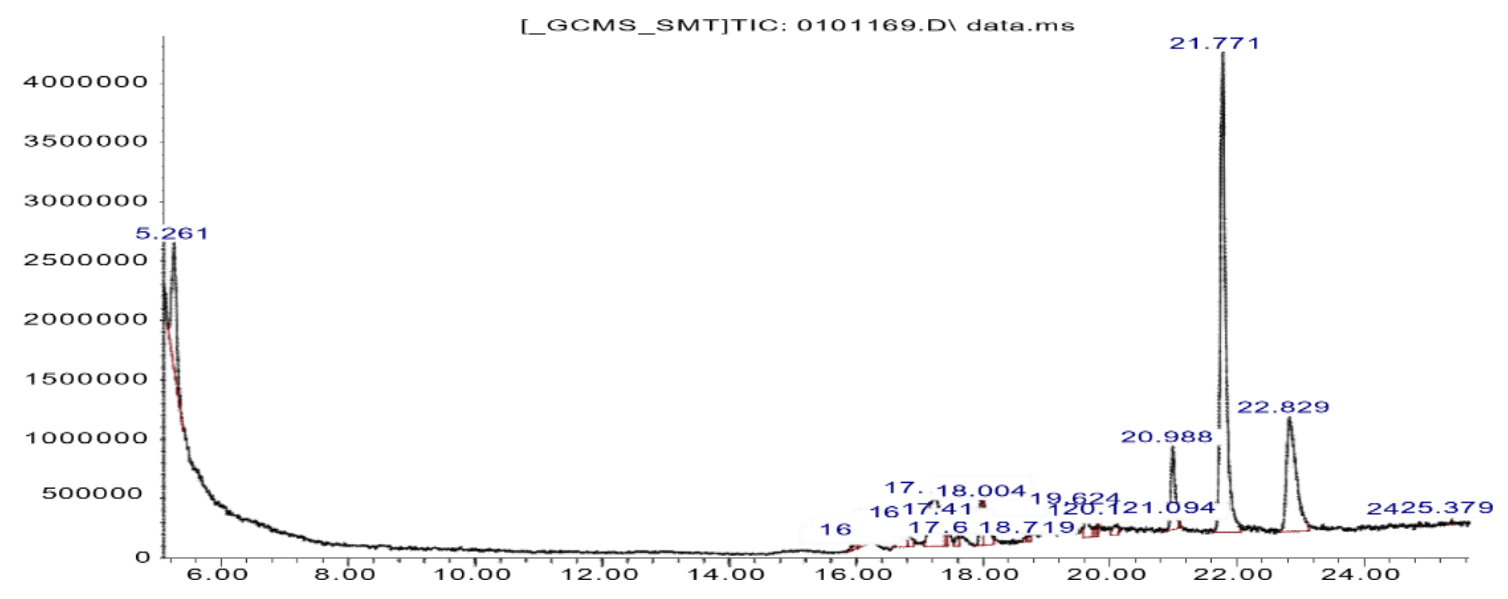

Figure 4: Gas Chromatography and mass spectrum (GCMS) test

Table 5: $\mathrm{pH}$ values for samples JA, JB and JC

\begin{tabular}{cc}
\hline & pH Test Evaluation \\
Samples & Values \\
\hline JA & 8.36 \\
JB & 8.40 \\
JC & 8.70 \\
\hline
\end{tabular}

Table 6: Viscosity values for samples JA, JB and JC.

\begin{tabular}{ccc}
\hline Samples & $\frac{x+y+z}{3}=\mathrm{K}$ & $\frac{K}{30 \mathrm{~mm}} \mathrm{~mm}^{2} / \mathrm{s}$ \\
\hline JA & 14.3 & 0.47 \\
JB & 15.7 & 0.52 \\
JC & 15.7 & 0.52 \\
\hline
\end{tabular}


Table 7: Viscosity and $\mathrm{pH}$ value of formulated cutting fluid

\begin{tabular}{cccc}
\hline Cutting fluid & $\begin{array}{c}\text { Optimized } \\
\mathrm{pH} \text { value }\end{array}$ & $\begin{array}{c}\text { Validated } \\
\mathrm{pH} \text { value }\end{array}$ & $\begin{array}{c}\text { Viscosity }\left(40^{\circ} \mathrm{C}\right) \\
\mathrm{mm}^{2} / \mathrm{s}\end{array}$ \\
\hline Jatropha oil based cutting fluid & 8.70 & 8.70 & 0.52 \\
\hline
\end{tabular}

Table 8: Most suitable stability test condition

\begin{tabular}{cc}
\hline Jatropha Seed Oil cutting fluid Samples & \% vol of water \\
\hline A & 95 \\
B & 93 \\
C & 92 \\
\hline
\end{tabular}

Table 9: Characteristics of oil-in-water emulsion cutting fluids

\begin{tabular}{ccc}
\hline S/N & Property & JBCF Values \\
\hline 1 & $\mathrm{pH}$ value & 8.36 \\
2 & Viscosity & $0.52 \mathrm{~mm}^{2} / \mathrm{s}$ \\
3 & Corrosion level & Resistant \\
4 & Stability & Stable \\
5 & Colour & Milky \\
\hline
\end{tabular}

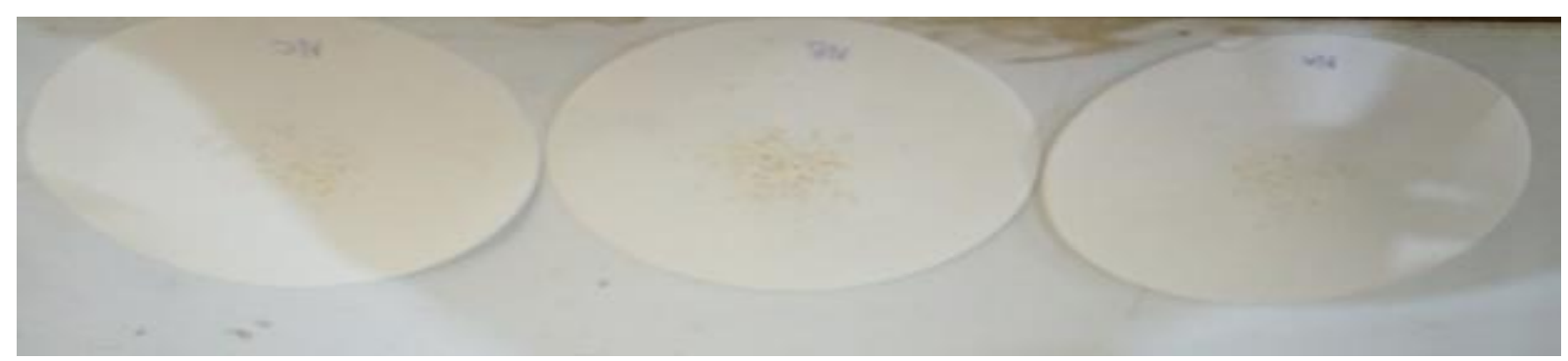

Figure 5: JSO formulated cutting fluids samples corrosion test

\subsubsection{Analysis of the Vegetable Oil based Cutting Fluid}

The characteristics of the oil-in-water emulsion cutting fluid formulated is shown in Table 9 The results for $\mathrm{pH}$ value, viscosity, corrosion level, stability and colour of the formulated cutting fluids which involved $10 \%$ of oil with the additives and $90 \%$ of water by volume for the jatropha oil based cutting fluid. All the samples in Figure 5 are the three jatropha samples (JA, JB and JC) which were put to test and all the samples passed the corrosion test. Therefore, the properties of the JBCF was compared with MBCF during the turning experiment to ascertain which of the cutting fluid performs better in terms of surface finish and tool wear

\subsection{Machining Process Results}

The experimental design layout shown is a response surface methodology layout which was employed to obtain the experimental process parameters and results for the two cutting fluids (JBCF and MBCF). A total of 20 runs was conducted for the three input parameters of cutting speed, VC (rev/min), feed rate, FR ( $\mathrm{mm} / \mathrm{revO}$ and depth of cut DOC $(\mathrm{mm})$. The responses considered during the turning process are tool wear, Tw $(\mathrm{mm})$ and surface roughness, Ra $(\mu \mathrm{m})$ over the two cutting fluids as shown in Table 10.

The laboratory experimental result for both machining responses (surface roughness and tool wear) carried out shows JBCF performed better than mineral oil based cutting fluid (MBCF) in terms of surface roughness, Ra, while, $M B C F$ is better in terms of tool wear. The experimental results show JBCF is a better lubricant and coolant compare to $M B C F$.

\section{3: Signal-to-Noise Ratio for the Surface Roughness and Tool Wear}

The characteristic equation for the signal to noise ratio ( $\mathrm{S} / \mathrm{N}$ ratio) for both surface roughness, $\mathrm{Ra}$ and tool wear, Tw for the different cutting fluids (JBCF and MBCF) is the smaller the better. The input parameters (cutting speed, Vc, feed $f$, and depth of cut doc, for the turning operation yielded the $S / N$ ratio for the two determined responses as shown in Table 11. The performance evaluation of JBCF compared to MBCF during turning operation with the same input parameters is consistent all through the 20 runs for each of the cutting fluids as shown in Table 11. S/N ratio for $J B C F$ is better than those of MBCF in terms of both surface roughness and tool wear. 
Table 10: Experimental result for different cutting fluids

\begin{tabular}{|c|c|c|c|c|c|c|c|}
\hline \multirow[b]{2}{*}{ RO } & \multirow[b]{2}{*}{$\begin{array}{c}V_{c} \\
\operatorname{Rev} / \min \end{array}$} & \multirow[b]{2}{*}{$\begin{array}{c}\text { FR } \\
(\mathrm{mm} / \mathrm{rev})\end{array}$} & \multirow[b]{2}{*}{$\begin{array}{l}\mathrm{DOC} \\
(\mathrm{mm})\end{array}$} & \multicolumn{2}{|c|}{ JBCF } & \multicolumn{2}{|c|}{ MBCF } \\
\hline & & & & $\begin{array}{c}\mathrm{Ra} \\
(\mu \mathrm{m})\end{array}$ & $\begin{array}{c}\mathrm{Tw} \\
(\mathrm{mm})\end{array}$ & $\begin{array}{c}\mathrm{Ra} \\
(\mu \mathrm{m})\end{array}$ & $\begin{array}{c}\text { Tw } \\
(\mathrm{mm})\end{array}$ \\
\hline 1 & 630 & 0.65 & 0.30 & 0.89 & 0.23 & 2.63 & 0.13 \\
\hline 2 & 1000 & 0.65 & 0.30 & 0.89 & 0.24 & 2.86 & 0.10 \\
\hline 3 & 630 & 1.00 & 0.30 & 0.89 & 0.25 & 2.89 & 0.11 \\
\hline 4 & 1000 & 1.00 & 0.30 & 0.85 & 0.15 & 2.62 & 0.12 \\
\hline 5 & 630 & 0.65 & 1.00 & 0.94 & 0.31 & 3.39 & 0.62 \\
\hline 6 & 1000 & 0.65 & 1.00 & 0.86 & 0.12 & 3.14 & 0.29 \\
\hline 7 & 630 & 1.00 & 1.00 & 0.86 & 0.16 & 3.71 & 0.31 \\
\hline 8 & 1000 & 1.00 & 1.00 & 1.38 & 0.29 & 4.77 & 1.02 \\
\hline 9 & 500 & 0.82 & 0.65 & 0.64 & 0.11 & 2.42 & 0.07 \\
\hline 10 & 1250 & 0.82 & 0.65 & 0.56 & 0.15 & 1.40 & 0.13 \\
\hline 11 & 800 & 0.52 & 0.65 & 0.91 & 0.09 & 1.42 & 0.13 \\
\hline 12 & 800 & 1.15 & 0.65 & 0.84 & 0.09 & 2.17 & 0.07 \\
\hline 13 & 800 & 0.82 & 0.10 & 0.87 & 0.46 & 2.29 & 0.07 \\
\hline 14 & 800 & 0.82 & 1.24 & 1.51 & 0.27 & 3.09 & 0.12 \\
\hline 15 & 800 & 0.82 & 0.65 & 0.87 & 0.17 & 4.48 & 0.12 \\
\hline 16 & 800 & 0.82 & 0.65 & 0.83 & 0.18 & 4.47 & 0.14 \\
\hline 17 & 800 & 0.82 & 0.65 & 0.87 & 0.15 & 4.45 & 0.12 \\
\hline 18 & 800 & 0.82 & 0.65 & 0.84 & 0.16 & 4.47 & 0.13 \\
\hline 19 & 800 & 0.82 & 0.65 & 0.85 & 0.16 & 4.47 & 0.14 \\
\hline 20 & 800 & 0.82 & 0.65 & 0.86 & 0.17 & 4.48 & 0.13 \\
\hline
\end{tabular}

Table 11: S/N ratio for Surface roughness and Tool wear

\begin{tabular}{cccccccc}
\hline & & & & \multicolumn{2}{c}{$S / \mathrm{N}$ ratio for JBCF } & \multicolumn{2}{c}{ S/N ratio for MBCF } \\
\hline RO & $\begin{array}{c}\mathrm{V}_{c} \\
\mathrm{Rev} / \mathrm{min}\end{array}$ & $\begin{array}{c}\mathrm{FR} \\
(\mathrm{mm} / \mathrm{rev})\end{array}$ & $\begin{array}{c}\mathrm{DOC} \\
(\mathrm{mm})\end{array}$ & $\begin{array}{c}\mathrm{Ra} \\
(\mu \mathrm{m})\end{array}$ & $\begin{array}{c}\mathrm{Tw} \\
(\mathrm{mm})\end{array}$ & $\begin{array}{c}\mathrm{Ra} \\
(\mu \mathrm{m})\end{array}$ & $\begin{array}{c}\mathrm{Tw} \\
(\mathrm{mm})\end{array}$ \\
\hline 1 & 630 & 0.65 & 0.30 & 1.34 & 18.49 & -9.82 & 18.70 \\
2 & 1000 & 0.65 & 0.30 & 1.40 & 16.23 & -7.69 & 22.82 \\
3 & 630 & 1.00 & 0.30 & 3.82 & 19.18 & -9.92 & 10.76 \\
4 & 1000 & 1.00 & 0.30 & -3.58 & 11.42 & -9.24 & 19.06 \\
5 & 630 & 0.65 & 1.00 & 1.56 & 20.41 & -6.72 & 22.61 \\
6 & 1000 & 0.65 & 1.00 & 1.32 & 15.69 & -11.39 & 10.08 \\
7 & 630 & 1.00 & 1.00 & 0.57 & 10.12 & -10.62 & 4.13 \\
8 & 1000 & 1.00 & 1.00 & 1.36 & 15.54 & -13.02 & 18.51 \\
9 & 500 & 0.82 & 0.65 & 1.20 & 15.33 & -12.99 & 17.15 \\
10 & 1250 & 0.82 & 0.65 & 1.57 & 15.00 & -12.97 & 18.22 \\
11 & 800 & 0.52 & 0.65 & 0.86 & 20.13 & -3.03 & 17.78 \\
12 & 800 & 1.15 & 0.65 & 0.93 & 12.63 & -9.14 & 19.63 \\
13 & 800 & 0.82 & 0.10 & 5.07 & 16.46 & -2.94 & 17.58 \\
14 & 800 & 0.82 & 1.24 & 1.07 & 12.52 & -8.39 & 17.46 \\
15 & 800 & 0.82 & 0.65 & 1.25 & 16.26 & -13.01 & 17.79 \\
16 & 800 & 0.82 & 0.65 & 1.48 & 15.80 & -13.00 & 17.34 \\
17 & 800 & 0.82 & 0.65 & -2.79 & 10.76 & -13.57 & -0.14 \\
18 & 800 & 0.82 & 0.65 & 1.41 & 16.18 & -13.02 & 17.88 \\
19 & 800 & 0.82 & 0.65 & 1.24 & 6.75 & -7.22 & 23.10 \\
20 & 800 & 0.82 & 0.65 & 0.99 & 12.01 & -8.37 & 18.43 \\
\hline
\end{tabular}

\subsection{Surface Roughness, $\mathrm{Ra}(\mu \mathrm{m})$}

\subsubsection{Main Effect Plot for Surface Roughness, Ra $(\mu \mathrm{m})$}

The main effect plot from SN ratio as shown in Figure 6 was used for optimum value determination for each input parameters during turning process for the surface roughness using JBCF. For surface roughness response, it is the lower the better characteristics that was chosen as shown equation 3.1. For the machining operation, the surface roughness optimal turning parameters are $1250 \mathrm{~m} / \mathrm{min}$ of cutting speed (level 5), $1.15 \mathrm{~mm} / \mathrm{rev}$ of feed (level 5), $0.65 \mathrm{~mm}$ depth of cut (level 3). Equation (1) is the calculated regressional analysis for JBCF surface roughness, $\mathrm{Ra}(\mu \mathrm{m})$. 


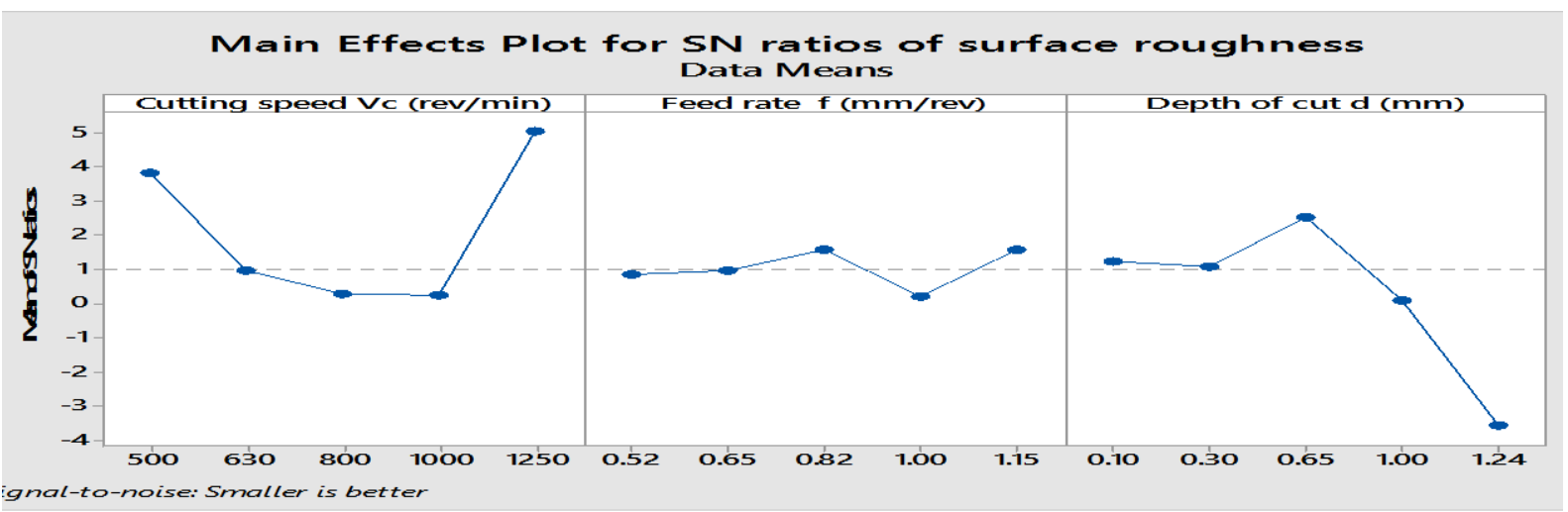

Figure 6: Main effect plot of $\mathrm{S} / \mathrm{N}$ ratio for surface roughness using JBCF

$\operatorname{Ra}(\mu \mathrm{m})=2.30+0.0007 \mathrm{Vc}-0.000002 \mathrm{Vc}_{c} * \mathrm{~V}_{c}+0.219 \mathrm{Fr} * \mathrm{Fr}-2.605 \mathrm{DOC}+1.078 \mathrm{DOC} * \mathrm{DOC}$ $+0.00230 \mathrm{Vc} * \mathrm{Fr}+0.000897 \mathrm{Vc} * \mathrm{DOC}+0.964 \mathrm{Fr} * \mathrm{DOC}$

R-sq $=85.14 \%$ and $R$-sq(adj) $=71.76 \%$

3.5 Tool Wear, Tw (mm)

3.5.1 Main Effect Plot for Tool Wear, Tw (mm)

The main effect plot for $\mathrm{SN}$ ratio as shown in Figure 7 was employed for optimum value determination for each input parameters during turning process for the tool wear using JBCF. For tool wear response, it is the lower the better characteristics that was chosen as shown in equation 3.1. For the machining operation, the tool wear optimal turning parameters are $500 \mathrm{~m} / \mathrm{min}$ of cutting speed (level 1), $1.15 \mathrm{~mm} / \mathrm{rev}$ of feed (level 5), $0.65 \mathrm{~mm}$ depth of cut (level 3). Equation (2) is the calculated regressional analysis for JBCF tool wear, Tw

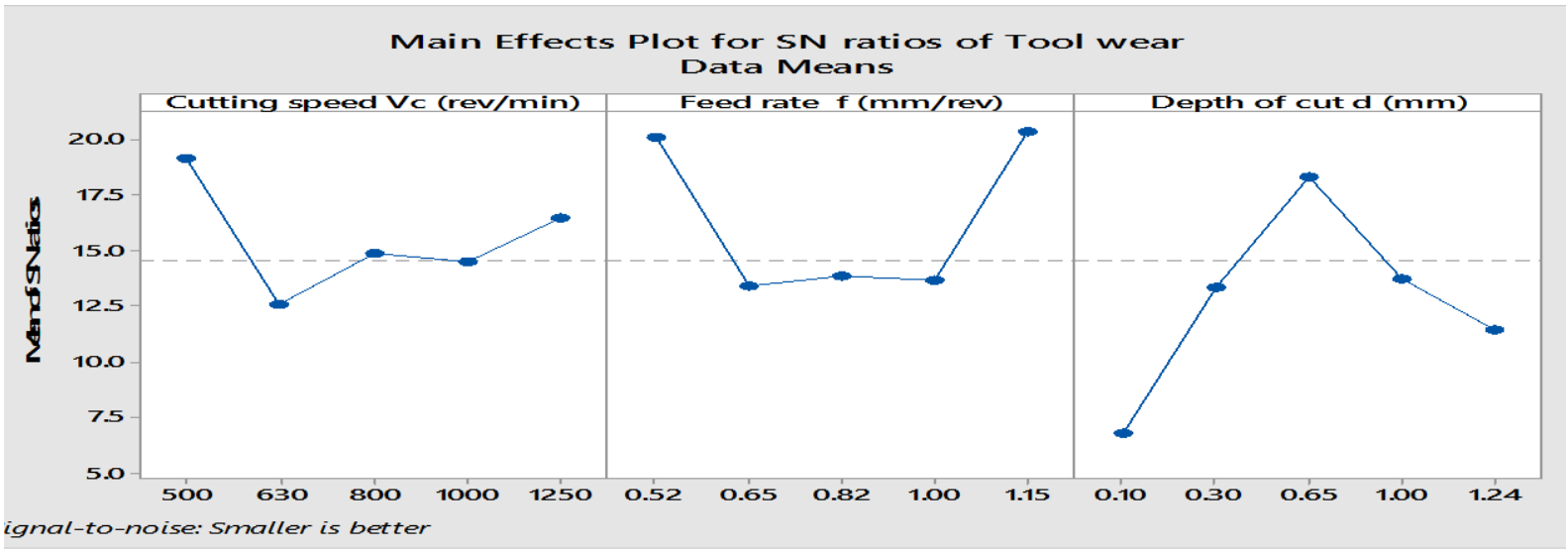

Figure 7: Main effect plot of $\mathrm{S} / \mathrm{N}$ ratio for tool wear using JBCF

$\mathrm{Tw}(\mathrm{mm})=0.708-0.000565 \mathrm{Vc}+0.20 \mathrm{FR}-1.115 \mathrm{DOC}-0.000000 \mathrm{Vc} * \mathrm{Vc}-0.608 \mathrm{FR} * \mathrm{FR}$

$$
+0.626 \mathrm{DOC} * \mathrm{DOC}+0.000821 \mathrm{Vc} * \mathrm{FR}+0.000084 \mathrm{Vc} * \mathrm{DOC}+0.192 \mathrm{FR} * \mathrm{DOC}
$$

R-sq $=71.24 \%$ and R-sq (adj) $=56.35 \%$

Both equation 1 and 2 R-sq and R-sq (adj) \% values are reliable and meet the machining process requirement.

\subsection{Surface Roughness, $\mathrm{Ra}(\mu \mathrm{m})$}

3.6.1 Main Effect Plot for Surface Roughness, Ra $(\mu \mathrm{m})$

The main effect plot for $\mathrm{SN}$ ratio as shown in Figure 8 was employed for optimum value determination for each input parameters during turning process for the surface roughness using MBCF. For surface roughness response, it is the lower the better characteristics that was chosen as presented in equation 3.1. For the machining operation, the surface roughness optimal turning parameters are $1250 \mathrm{~m} / \mathrm{min}$ of cutting speed (level 5), $0.52 \mathrm{~mm} / \mathrm{rev}$ of feed (level 1), $0.65 \mathrm{~mm}$ depth of cut (level 3). Equation (3) is the calculated regressional analysis for MBCF surface roughness, $\mathrm{Ra}(\mu \mathrm{m})$

$$
\begin{aligned}
& \mathrm{Ra}(\mu \mathrm{m})=-20.10+0.02227 \mathrm{Vc}+33.59 \mathrm{Fr}+1.47 \mathrm{DOC}-0.000016 \mathrm{Vc} * \mathrm{Vc}-22.52 \mathrm{Fr} * \mathrm{Fr} \\
& -3.8 \mathrm{DOC} * \mathrm{DOC}+0.00310 \mathrm{Vc} * \mathrm{Fr}+0.00172 \mathrm{Vc} * \mathrm{DOC}+3.96 \mathrm{Fr} * \mathrm{DOC} \\
& \text { R-sq }=84.44 \% \text { and R-sq(adj) }=70.43 \%
\end{aligned}
$$




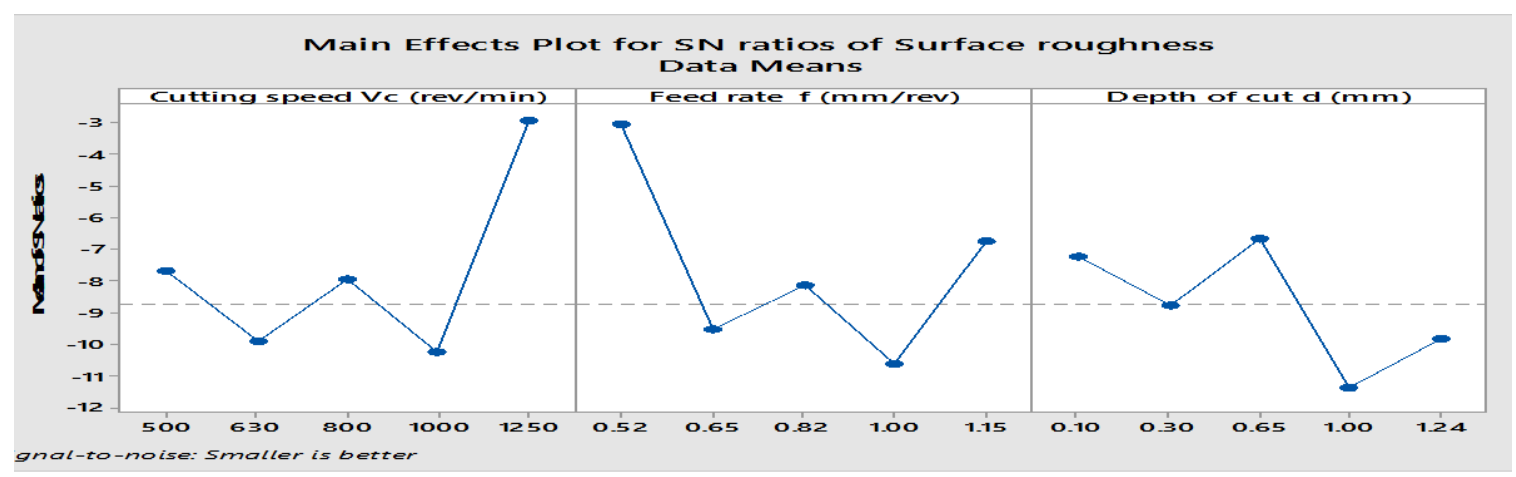

Figure 8: Main effect plot of $\mathrm{S} / \mathrm{N}$ ratio for surface roughness using $\mathrm{MBCF}$

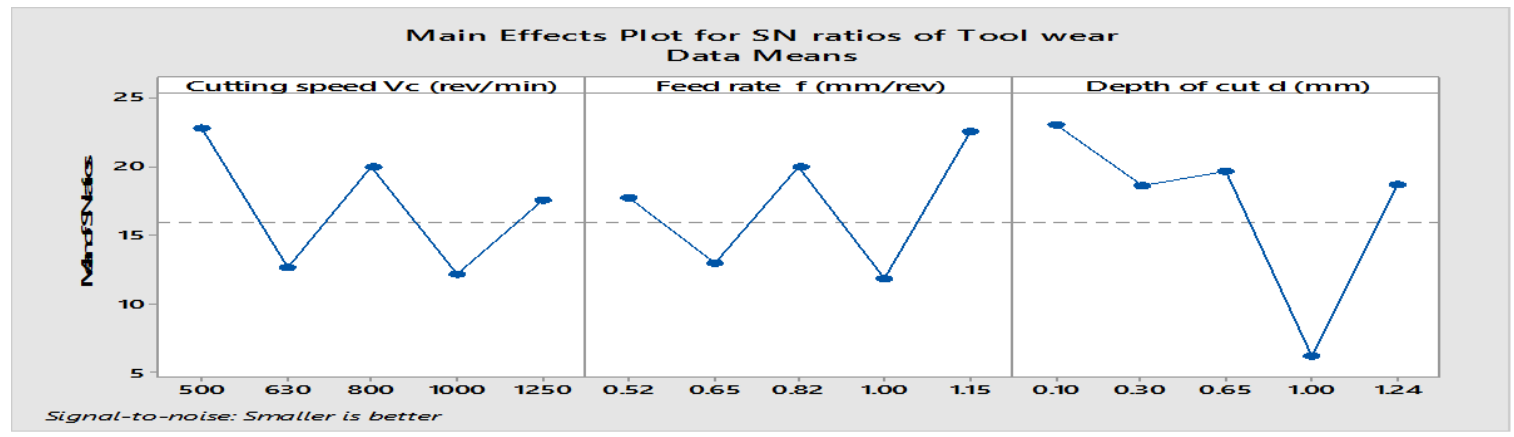

Figure 9: Main effect plot of S/N ratio for tool wear using MBCF

\subsection{Tool Wear, Tw (mm)}

\subsubsection{Main Effect Plot for Tool Wear, Tw (mm)}

The main effect plot for $\mathrm{SN}$ ratio as shown in Figure 9 was employed for optimum value determination for each input parameters during turning process for the tool wear using MBCF. For surface roughness response, it is the lower the better characteristics that was chosen as presented in equation 4.1. For the machining operation, the surface roughness optimal turning parameters are $500 \mathrm{~m} / \mathrm{min}$ of cutting speed (level 1), $1.15 \mathrm{~mm} / \mathrm{rev}$ of feed (level 5), 0.10 $\mathrm{mm}$ depth of cut (level 1). Equation (4) is the calculated regressional analysis for MBCF tool wear, Tw.

$$
\begin{aligned}
& \mathrm{TW}(\mathrm{mm})= 4.35-0.00437 \mathrm{Vc}-5.35 \mathrm{FR}-1.43 \mathrm{DOC}+0.000000 \mathrm{Vc} * \mathrm{Vc}+0.88 \mathrm{FR} * \mathrm{FR} \\
&+0.288 \mathrm{DOC} * \mathrm{DOC}+0.00423 \mathrm{Vc} * \mathrm{FR}+0.00086 \mathrm{Vc}^{*} \mathrm{DOC}+0.91 \mathrm{FR} * \mathrm{DOC} \\
& \mathrm{R}-\mathrm{sq}=70.48 \% \text { and R-sq(adj) }=55.92 \%
\end{aligned}
$$

Also, equation 3 and 4 R-sq and R-sq (adj) \% values are reliable and meet the machining process requirement.

\subsection{Analysis of Variance for Surface Roughness}

\section{(a) Analysis of Variance for Surface Roughness Using JBCF}

ANOVA statistics as shown in Table 12 was used to study the significance of the input parameters on the surface roughness when cutting with JBCF. The significant effect of cutting speed, feed and depth of cut on the surface roughness during cutting with JBCF are as follows: cutting speed, CS (27.39\%), feed rate, FR (6.16\%) and depth of cut, DOC (62.73\%). These results show that depth of cut has more significant impact on the surface roughness, followed by cutting speed. This indicated that depth of cut and cutting speed are more significant than feed on the surface roughness. Figure 10 shows the contour plots of the effect of depth of cut $(\mathrm{mm})$ and cutting speed $(\mathrm{m} / \mathrm{min})$ on surface roughness, $\mathrm{Ra}(\mu \mathrm{m})$. It was observed that as cutting speed increase with decrease in depth of cut, the surface roughness decreases when JBCF is employed. The effect of cutting speed and depth of cut on the surface roughness is shown using 3D surface plot in Figure 11. The flattened curve shape fit the design model. It is observed that has depth of cut increased with cutting speed, the surface roughness decreases which is in agreement with the contour plot.

\section{(b) Analysis of Variance for Surface Roughness Using MBCF}

ANOVA statistics with MBCF as shown in Table 13 was employed to study the significance of the input parameters on the surface roughness when cutting. The significant effect of cutting speed, feed and depth of cut on the surface roughness during cutting with MBCF are as follows: cutting speed, CS (33.69\%), feed rate, FR (38.29\%) and depth of cut, DOC $(24.53 \%)$. These results show that feed rate has significant edge impact on the surface roughness, followed by cutting speed. This indicated that feed rate and cutting speed are more significant than depth of cut on the surface roughness when cutting with MBCF. 
Table 12: ANOVA for surface roughness, $\mathrm{Ra}$

\begin{tabular}{|c|c|c|c|c|c|}
\hline Factor & DOF & SS & MS & $\mathrm{F}$ & $P$ \\
\hline $\mathrm{CS}(\mathrm{m} / \mathrm{min})$ & 4 & 0.22 & 0.06 & 12.90 & 27.39 \\
\hline $\mathrm{FR}(\mathrm{mm} / \mathrm{rev})$ & 4 & 0.05 & 0.01 & 2.89 & 6.16 \\
\hline $\mathrm{DOC}(\mathrm{mm})$ & 4 & 0.51 & 0.13 & 29.54 & 62.73 \\
\hline Error & 7 & 0.03 & 0.00 & & 3.72 \\
\hline Total & 19 & 0.81 & 0.04 & & 100 \\
\hline
\end{tabular}

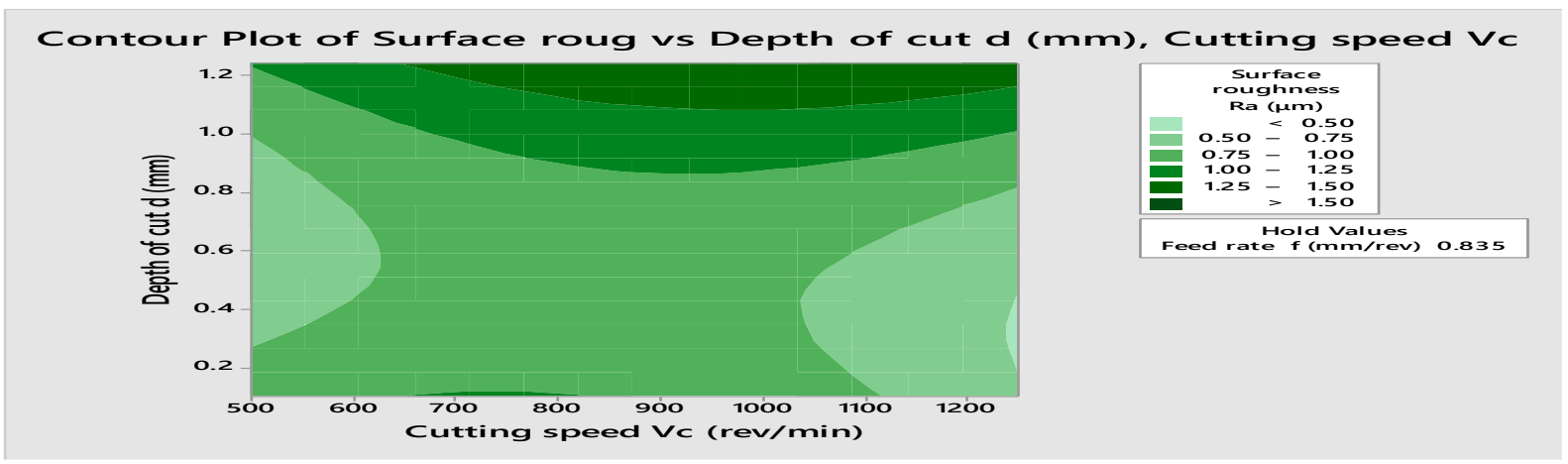

Figure 10: Contour plot for surface roughness with JBCF

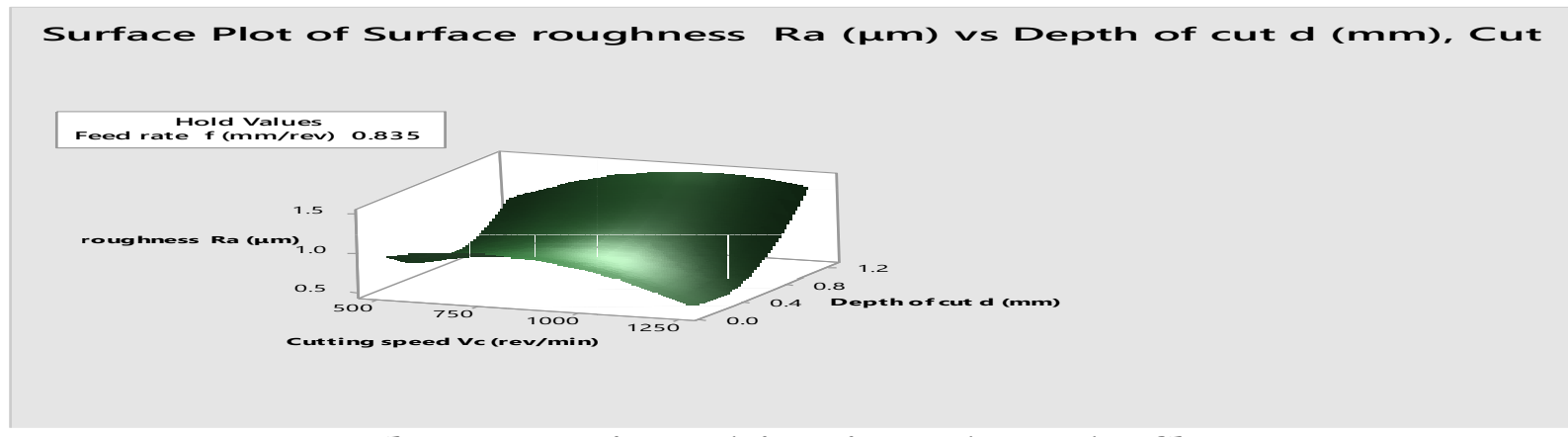

Figure 11: 3D surface graph for surface roughness with JBCF

Table 13: ANOVA for surface roughness, Ra

\begin{tabular}{lccccc}
\hline \multicolumn{1}{c}{ Factor } & DOF & SS & MS & F & P \\
\hline CS $(\mathrm{m} / \mathrm{min})$ & 4 & 7.43 & 1.86 & 16.88 & 33.69 \\
FR $(\mathrm{mm} / \mathrm{rev})$ & 4 & 8.44 & 2.11 & 19.18 & 38.29 \\
DOC $(\mathrm{mm})$ & 4 & 5.41 & 1.35 & 12.29 & 24.53 \\
Error & 7 & 0.77 & 0.11 & & 3.49 \\
Total & 19 & 22.04 & 1.16 & & 100 \\
\hline
\end{tabular}

Figure 12 shows the contour plots of the effect of feed rate $(\mathrm{mm} / \mathrm{rev})$ and cutting speed $(\mathrm{m} / \mathrm{min})$ on surface roughness, $\mathrm{Ra}(\mu \mathrm{m})$. It was observed that as feed rate increase with decrease in cutting speed, the surface roughness increase when MBCF is employed compared to JBCF and NBCF. The effect of cutting speed and depth of cut on the surface roughness is shown on 3D surface plot in Figure 13 with a design model fitted flattened curve shape. It is observed that has feed rate increased with cutting speed, the surface roughness increase which is in agreement with the contour plot.

\subsection{Analysis of Variance for Tool Wear}

\section{(a) Analysis of Variance for Tool Wear Using JBCF}

ANOVA statistics as shown in Table 14 was employed to study the significance of the input parameters on the tool wear when cutting with JBCF. The significant effect of cutting speed, feed and depth of cut on the tool wear during cutting with JBCF are as follows: cutting speed, CS (10.62\%), feed rate, FR (15.29\%) and depth of cut, DOC $(70.83 \%)$. These results show that depth of cut has high impact on the tool wear, followed by feed rate. This indicated that depth of cut and feed rate are more significant than cutting speed on the tool wear using JBCF. 
Figure 14 shows the contour plots of the effect of depth of cut $(\mathrm{mm})$ and feed rate $(\mathrm{mm} / \mathrm{rev})$ on tool wear, Tw (mm). It was observed that as feed rate increase with decrease in depth of cut, the tool wear decrease when JBCF is employed. The effect of feed rate and depth of cut on the tool wear is shown using 3D surface plot in figure 15. The flattened curve shape fit the design model. It is observed that has feed rate increased with depth of cut, the tool wear decrease which is in agreement with the contour plot.

\section{(b) Analysis of Variance for Tool Wear Using MBCF}

ANOVA statistics as shown in Table 15 was employed to study the significance of the input parameters on the tool wear when cutting with MBCF. The significant effect of cutting speed, feed and depth of cut on the tool wear during cutting with NBCF are as follows: cutting speed, CS (20.25\%), feed rate, FR $(20.82 \%)$ and depth of cut, DOC $(58.37 \%)$. These results show that depth of cut has significant edge impact on the tool wear, followed by feed rate and cutting speed at close range. This indicated that depth of cut is by far more significant than feed rate and cutting speed on the tool wear when turning with MBCF.

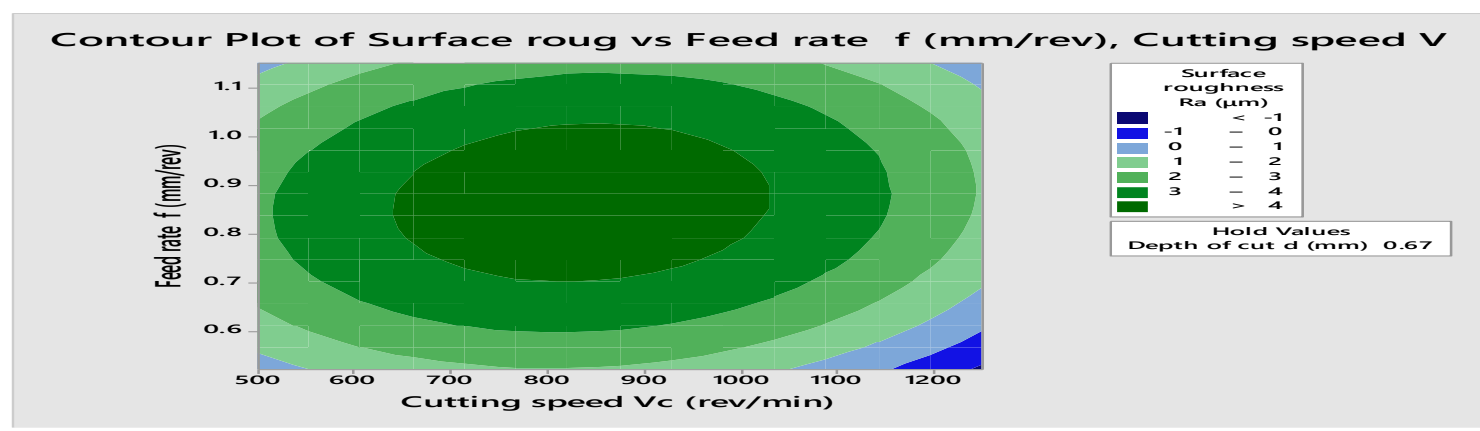

Figure 12: Contour plot for surface roughness with MBCF

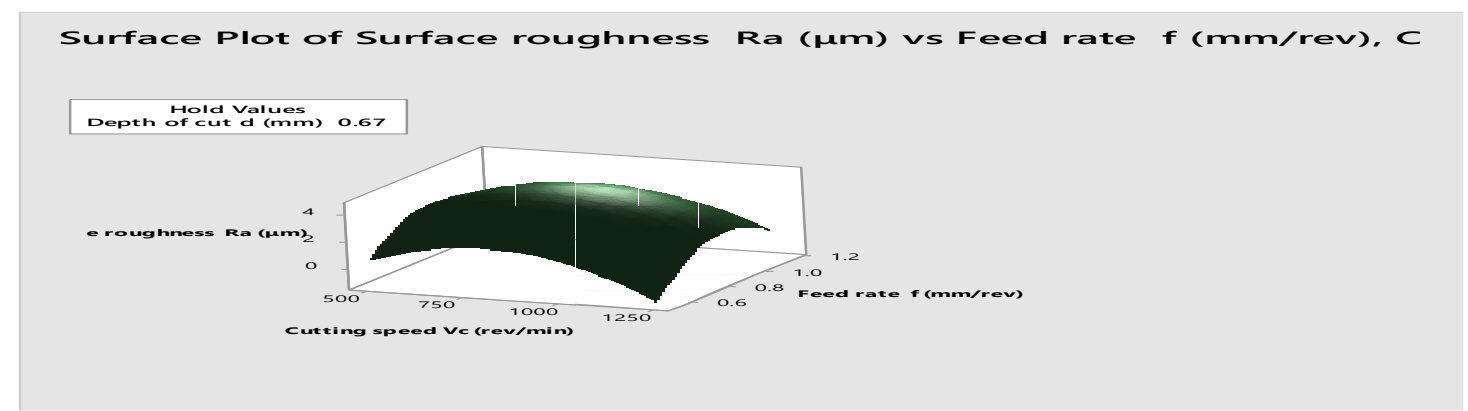

Figure 13: 3D surface graph for surface roughness with $M B C F$

\begin{tabular}{lccccc}
\multicolumn{7}{c}{ Table 14: ANOVA for tool wear, Tw $(\mathrm{mm})$} \\
\hline Factor & DOF & SS & MS & F & P \\
\hline CS $(\mathrm{m} / \mathrm{min})$ & 4 & 0.02 & 0.00 & 5.71 & 10.62 \\
FR $(\mathrm{mm} / \mathrm{rev})$ & 4 & 0.02 & 0.01 & 8.23 & 15.29 \\
DOC $(\mathrm{mm})$ & 4 & 0.10 & 0.03 & 38.06 & 70.83 \\
Error & 7 & 0.00 & 0.00 & & 3.26 \\
Total & 19 & 0.15 & 0.01 & & 100 \\
\hline
\end{tabular}

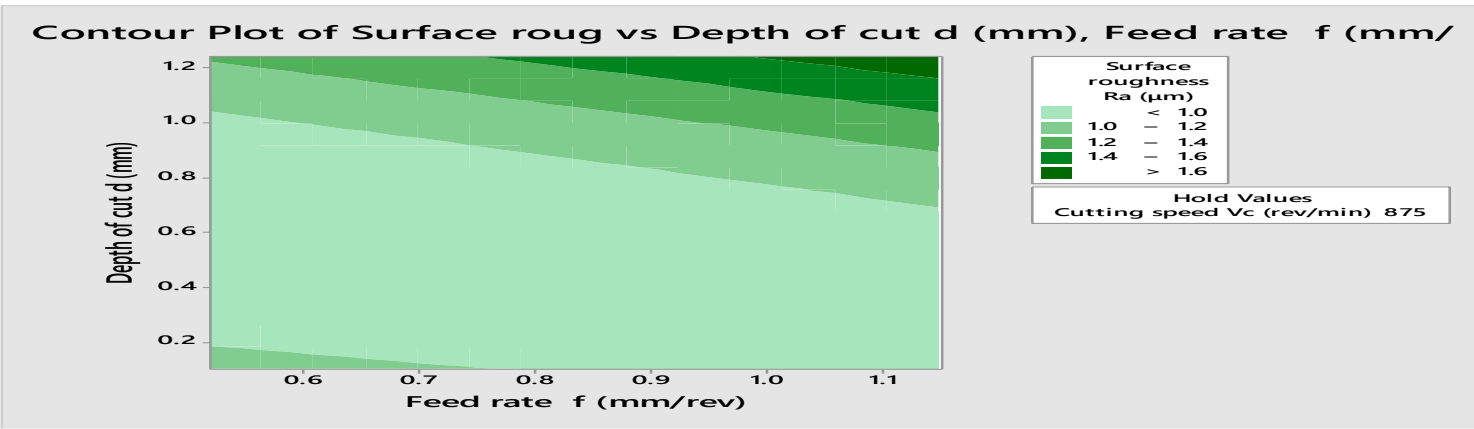

Figure 14: Contour plot for tool wear with JBCF 


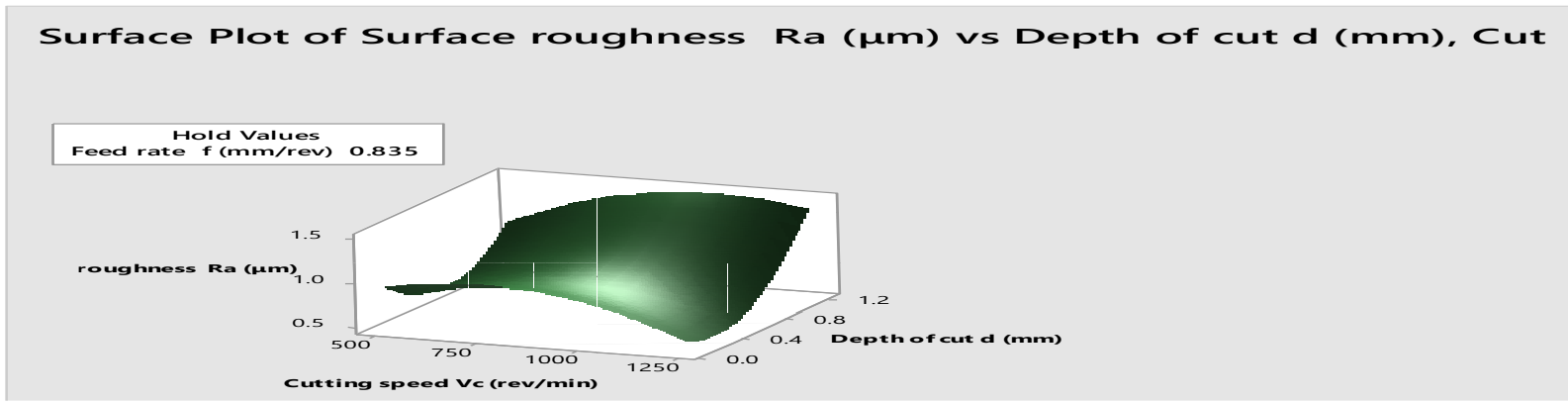

Figure 15: 3D surface graph for tool wear with JBC

Table 15: ANOVA for tool wear, Tw (mm)

\begin{tabular}{lccccc}
\hline Factor & DOF & SS & MS & F & P \\
\hline CS $(\mathrm{m} / \mathrm{min})$ & 4 & 0.20 & 0.05 & 62.80 & 20.25 \\
FR $(\mathrm{mm} / \mathrm{rev})$ & 4 & 0.21 & 0.05 & 64.56 & 20.82 \\
DOC $(\mathrm{mm})$ & 4 & 0.58 & 0.14 & 181.00 & 58.37 \\
Error & 7 & 0.01 & 0.00 & & 0.56 \\
Total & 19 & 0.99 & 0.05 & & 100 \\
\hline
\end{tabular}

Figure 16 shows the contour plots of the effect of depth of cut $(\mathrm{mm})$ and feed rate $(\mathrm{mm} / \mathrm{rev})$ on surface roughness, $\mathrm{Ra}(\mu \mathrm{m})$. It was observed that as depth of cut increase with decrease in feed rate, the tool wear decrease when MBCF is employed. The effect of cutting speed and depth of cut on the tool wear with a flattened curve shape design model is shown in the 3D surface plot in Figure 17. It is observed that has depth of cut increased with feed rate, the tool wear increase which is in agreement with the contour plot.

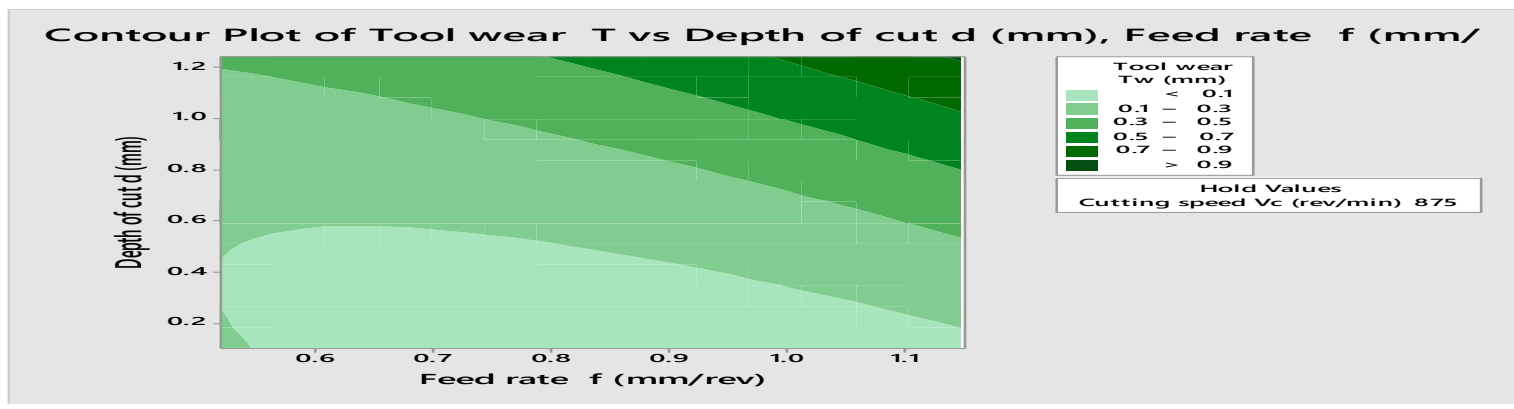

Figure 16: Contour plot for tool wear with MBCF

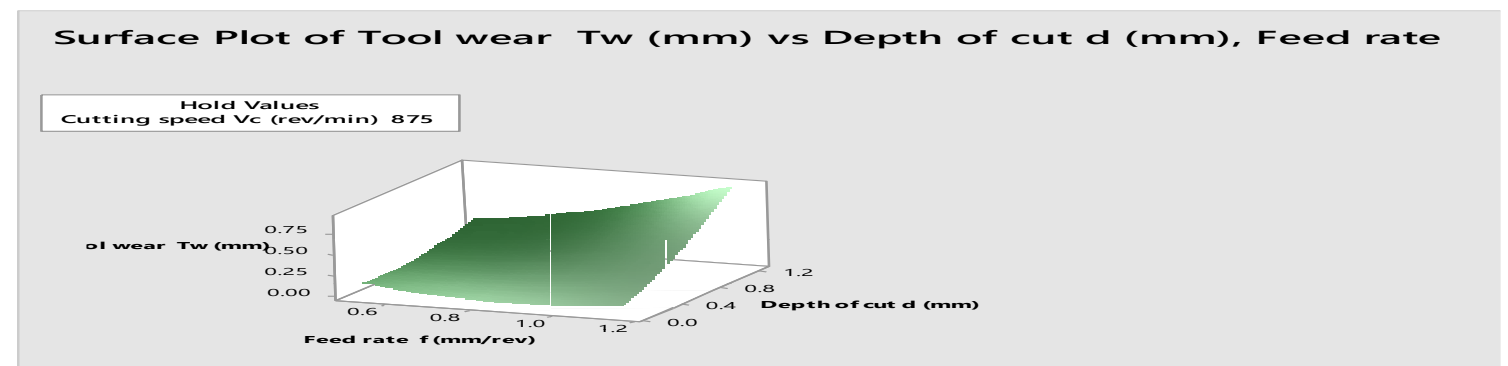

Figure 17: 3D surface graph for tool wear with $M B C F$

\section{CONCLUSIONS}

This study presents the comparative evaluation of formulated jatropha based cutting fluid (JBCF) with mineral based cutting fluid (MBCF). The jatropha seed oil (JSO) that was sourced was characterized. The physiochemical properties and fatty acid composition (FAC) of the JSO was analysed. The adopted sample formulae were used for the three samples at the ratio 1:9 with the required standard procedures. RSM was employed in the experimental process to 
ascertain the performance of JBCF and MBCF in the turning operation. Based on the experimental results obtained, the following conclusions can be drawn:

(i) The physiochemical properties and the fatty acid composition result of the sourced JSO is consistent with the various existing JSOs.

(ii) The behavioural properties in terms stability, corrosion resistant, $\mathrm{pH}$ and viscosity signify the environmental friendliness

(iii) The experimental results show minimal surface roughness with JBCF and minimal tool wear with MBCF. While, the $\mathrm{S} / \mathrm{N}$ ratio of JBCF performed better compared to MBCF.

(iv) The regressional characteristic of JBCF is more reliable compared to MBCF with R-sq $=85.14 \%$ and $\mathrm{R}$-sq(adj) $=71.76 \%$ for JBCF Ra and R-sq $=71.24 \%$ and $\mathrm{R}$-sq(adj) $=56.35 \%$ for JBCF Tw, while, R-sq $=84.44 \%$ and $\mathrm{R}$-sq(adj) $=70.43 \%$ is for MBCF Ra and R-sq $=70.48 \%$ and $\mathrm{R}$-sq(adj) $=55.92 \%$ for MBCF Tw.

\section{REFERENCES}

1. Lawal, S. A., Choudhury, I.A., \& Nukman, Y. (2014). Experimental Evaluation and Optimization of Flank Wear During Turning of AISI 4340 Steel with Coated Carbide Inserts Using Different Cutting Fluids. Journal of Institution of Engineers, India (Series. C) 96(1), 21 -28. DOI 10.1007/s40032-014-0154-9.

2. Kuram E., Ozcelik, B., \& Demirbas, E. (2013). Environmentally Friendly Machining: Vegetable Based Cutting Fluids. J.P. Davim (ed.). Green Manufacturing Processes and Systems, Material Forming and Tribology. DOI: 10.1007/978-3-642-33792-52. Springer-Verlag, Berlin Heidelberg.

3. Ademoh N.A., Didam J.H. and Garba D.K. (2016). Investigation of Neem Seed Oil as an Alternative Metal Cutting Fluid. American Journal of Mechanical Engineering 4(5), 191-199.

4. Richard, N. C. and Kevin, M. H. (2004). The development and analysis of an environmental friendly machining fluid application system; International Journal of Environmentally Conscious Design and Manufacturing. 12(3), 142-152.

5. Singh, A. K., and Gupta, A K. (2006). Metal working fluids from vegetable oils. Journal of Synthetic Lubrication, 167-176.

6. Salete Martins Alves, Joao Fernando Gomes de Oliveira (2006). Development of new cutting fluid for grinding process adjusting mechanical performance and environmental impact. Journal of Materials Processing Technology, 179 (1-3), 185-189.

7. Anzalone, A., (2011). Principles of Machining Processes. Chapter 12 Manufacturing Processes and Materials (ETI 1420) Training Course. http://www.youtube.com/watch?v=VHTXaU7CZCO (20 May 2020).

8. Lawal S.A., Choudhury I.A., \& Nukman Y. (2012). Application of vegetable oil-based metal working fluids in machining ferrous metals-A review. International Journal of Machine Tools and Manufacture, 52 (1), 1-12.

9. Onuoha, O. J, (2016). Determining the Effect of Cutting Fluids on Surface Roughness in Turning AISI 1330 Alloy Steel Using Taguchi Method. Modern Mechanical Engineering, 6, 51-59.

10. Muniz, C. A. S., Dantas, T. N. C., Moura, E.F., Neto, A. A. D., \& Gurgel, A. (2008). Novel Formulations of Cutting Fluids using Naphtenic Basic Oil. Brazilian Journal of Petroleum and Gas. 2(4), 143-153.

11. Rao, D. N., Srikant, R. R., \& Rao, Ch. S. (2007). Influence of Emulsifier Content on Properties and Durability of Cutting Fluid. Journal of Engineering, Brazilian Society of Mechanical, Science and Engineering. 29(4), 396400.

12. Diamante, L.M and Lan, T. (2014). Absolute viscosities of vegetable oils at different temperatures and shear rate range of 64.5 to $4835 \mathrm{~s}^{-1}$. Journal of Food Processing. Article ID 234583, https://doi.org/10.1155/2014/234583 